Amazonía Peruana, Tomo XV, No 30, 2007; p.p 17-49

\title{
LA REACCIÓN CONTRA LA DESCOLONIZACIÓN DE LA INTELECTUALIDAD*
}

\author{
Joanna Overing
}

Este artículo aborda la cuestión de la descolonización de las relaciones de poder inherentes a la historia de la intelectualidad occidental por medio de la antropología de lo lúdico y de la inspiración de la política y la poética narrativa de los pueblos amazónicos, en particular de los piaroa del Orinoco venezolano. Recorre algunos relatos del multiverso de la cosmología piaroa, mostrando como los dioses creadores de la gente, de los alimentos y de las poderosas artes culinarias, actúan como monstruos grotescos envenenados por su exceso de poder, dominados por la hybris, la paranoia y la megalomanía. La vida diaria piaroa, ridiculiza humorísticamente a todos los tiranos, y surge del desafío colocado para cada persona, hombre o mujer, de controlar estas poderosas "fuerzas de pensamientos" liberadas por los dioses en los tiempos de la creación para generar una existencia social propiamente humana.

This paper addresses the issue of the decolonization of power relations inherent to the history of Western intellectuality through the means of the anthropology of play and the inspiration derived from the politics and poetic narrative of Amazonian peoples, especially, the piaroa of the Venezuelan Orinoco. It journeys through various chanted mythical narratives of the piaroa multiverse and cosmology, showing how the creator gods of people, food and the powerful culinary arts behave like grotesque monsters poisoned by their excess of power, dominated by hubris, paranoia and megalomania. Piaroa dialy life, humouristically ridicules all tyrans and springs from the challenge faced by each person, man or woman, to control these powerful "strengths of thoughts" released by the goods in the creation times in order to generate a properly human social existence.

Una versión diferente de este artículo fue publicado en Brasil. "A reação contra a descolonização da intelectualidade", en Ilha:Revista de Antropología, 2004. La traducción del inglés del presente artículo ha sido realizada por Luisa Elvira Belaunde. 
¿Cómo podemos devolver una mirada antropológica que evite la falacia de la superioridad de la civilización occidental? Esta es la cuestión. ¿Cómo podemos desarrollar una escritura antropológica que no silencie al Otro? ¿Cómo podemos descolonizar la intelectualidad? ¿Traducir los conocimientos y modos de pensar de otros pueblos (ver también Fardon 1995)? ¿Captar sus voces (utilizando la expresión actual) y lo que dicen al respecto del conocimiento y el pensamiento? Esto es, antes que nada, una empresa política, pero también es una cuestión crucial para el futuro éxito intelectual y académico de la disciplina. El descolonizar la intelectualidad, se adecua bien a los talentos específicos de la antropología, con su énfasis en el multiperspectivismo y el valor que tiene para nosotros. ¿Pero, será que la propia historia de la antropología con el actual ambiente político global, estaría actuando contra el esfuerzo de descolonización? Concluiré con algunos comentarios sobre este problema. El multi-perspectivismo siempre fue algo difícil de que asirse. Siempre existió una fuerte presión en su contra.

Como sabemos bien, la antropología nació como una disciplina académica a finales del siglo XIX e inicios del XX, durante el auge de lo que hoy denominamos el "pensamiento moderno". Este periodo también correspondió al ápice de las empresas imperialistas occidentales. Puesto que la antropología no podía ser sino el producto de su época, el ambiente político e intelectual de ese tiempo estaba sumergido en el desarrollo del imperialismo, y ha permanecido de esta manera hasta hoy. Existía el sueño de cavar un espacio intelectual propio para la antropología, en el que podría desarrollarse como la guardiana de la verdad y la objetividad. La antropología necesitaba construir su propio objeto (un tema sobre el cual Fabian (1983) ha reflejado notablemente). Este objeto, lógicamente, era el Otro colonizado por el occidente (la sociología, por su parte, tenía la tarea de tomar por objeto las propias clases subalternas al interior del occidente). El "objeto" de la antropología vino a ser los "marginalizados" del mundo, las clases subalternas, los."no-familiares" (unhomely), como Homi Bhabha (1994) los llama. ¡La antropología como un estudio de la "periferia"! Se creó la "ciencia de la alteridad" para el occidente, y juntamente, el vocabulario técnico y las imágenes objetificadas con las que los pueblos conquistados y asimilados por los Estados occidentales podían ser fácilmente digeridos (como primitivos) por el modo de pensar europeo. Naturalizamos a estos pueblos, transformándolos en objetos de una naturaleza que necesitaba ser trascendida por la civilización moderna, dominándola y domesticándola (Mason 1990:13-15).

Gran parte del lenguaje analítico de la antropología habla sobre los "primitivos". Escribimos sobre los pueblos que hacen parte de las sociedades "preletradas, pre-Estado", "pre-tecnológicas", "pre-industriales". O sea, que son débiles, no-desarrolladas, y subdesarrolladas en sus culturas, su vida política, sus relaciones económicas y sus mentes. Parados en el tiempo, mientras nosotros tenemos progreso. Los debates antropológicos sobre la vida política y social de los pueblos amazónicos están repletos de ideas como estas. En su comentario sobre el estado de la etnografía 
amazónica, Peter Rivière (1984) constató que, en el lenguaje antropológico, los pueblos amazónicos son más conocidos por lo que no son que por lo que son: sin estado, sin ningún gobierno ni autoridad política, y con poca estructura social ... En otras palabras, no tienen un orden político ni tampoco, de hecho, un orden social. Según el credo de los mitos occidentales, esto implica que los pueblos amazónicos tienen poca creatividad, poco orden moral o estético... Al colocar este presupuesto sobre los pueblos con diferentes estados de sociedad, orden político o creatividad, hemos obliterado a los pueblos amazónicos. Con estas expresiones occidentales, hemos perdido completamente de vista lo que es importante para los pueblos amazónicos, y lo que constituye su horizonte de preocupaciones.

¿Será que estoy siendo demasiado severa?

Bien, entonces intenten comprender la dignidad del igualitarismo amazónico, con su retórica peculiar y sus fundamentos intelectuales - un antiguo sueño mío. ¿Qué tipo de orden político puede ser generado por este peculiar igualitarismo? Entonces, intenten abordar las repercusiones políticas de la poética amazónica. Intenten traducir sus tropos y su lugar para la creación de la socialidad amazónica. Intenten, entonces, hablarnos sobre la dignidad política que vinculada al estatus de ser una mujer adulta en una comunidad amazónica. Intenten hablar de la libertad política de la mujer. Intenten expresar cualquiera de estas cosas por medio de la mirada condescendiente y del vocabulario de la teoría social occidental. Me acuerdo claramente de un colega, muy conocido en el área, quien, demostró una irritación feroz ante la idea de que la creatividad pudiese ser una noción relevante para comprender los modos de vida de los pueblos amazónicos.

Para comenzar a entender los modos de pensamiento amazónicos, debemos, obviamente, colocarnos la tarea de descolonizar la intelectualidad que produce los conocimientos sobre la amazonía, y, con este finalidad, debemos hacer un gran esfuerzo por descentralizar los relatos occidentales sobre lo social y lo político (ver Overing \& Passes 2000). El lenguaje en que estos grandes mitos occidentales son contados revela una buena historia sobre el occidente, una historia que depende de la inferiorización del Otro. Conociendo a los pueblos amazónicos, sus orientaciones y sus distinciones de valor, queda claro que el lenguaje especializado de la teoría occidental es un instrumento de la tecnología política de la negación. Evidentemente, no podemos iniciar el trabajo de descolonizar la intelectualidad sobre la amazonía utilizando dicho lenguaje. El evolucionismo social subyacente, vinculado a los preceptos del racionalismo iluminista y a las distinciones de valor modernas, está demasiado presente. Desafío a cualquiera a decir alguna cosa que suene auténtica sobre el igualitarismo, la poética, la socialidad o la política amazónica, utilizando el lenguaje de la teoría occidental moderna.

Esta traducción es realmente una tarea que exige una erosión constante de la armadura del modernismo. Ese es un proceso que debería suceder naturalmente en 
las conversaciones con los pueblos amazónicos. Comenzariamos, entonces, a entender mejor la retórica de nuestra teoría social. Descubrí que la retórica piaroa y de otros pueblos amazónicos esclarecen bien nuestras grandiosas narraciones sobre la evolución, el individuo, la sociedad y la racionalidad.

Evidentemente, la antropología tiene mucho que responder. ¿La antropología realmente estaba a servicio del colonialismo? La respuesta no es tan clara. Cuando el acento estaba puesto sobre la superioridad del investigador antropólogo, la mirada se rehusaba a prestar atención a buena parte de lo que el resto del mundo tenía que decir, ya que la meta era el progreso de la ciencia; cuando la preocupación principal era las abstracciones y el plano sociológico, los universales (es decir, aquello que, en verdad, se aplicaba al occidente) y el modelo racionalista, formalista y jurídico de "derechos" centrado en la visión occidental - y no en los seres humanos concientes, vivos, sensuales, experimentando, reflexionando, riendo, llorando, contando, aconsejando, cantando, haciendo juegos de palabras, jugando - entonces la antropología si le sirvió a los programas modernistas del colonialismo (ver Rapport \& Overing 2000).

Bueno, hay una cosa cierta. La antropología de hoy no es más lo que fue hace dos décadas, puesto que ya experimentamos un dislocamiento enorme de punto de vista. En gran parte, esto se debe al florecimiento de la literatura post-colonial. Ya que la antropología fue la disciplina más abiertamente involucrada en la construcción de un imaginario objetificado del Otro, se convirtió en el blanco evidente de mucha crítica post-colonial (por ejemplo, ver Asad 1975; Said 1978; Tomas 1994; de Certeau 1997; Bauman 1995; Fabian 1983). De cierta forma, hemos entrado en un estado de confusión y arrepentimiento cada vez que se publicó un nuevo estudio post-colonial. El antropólogo se vio sustituyendo al misionero como el "villano" del mundo occidental. Aun así, el soplo de viento post-colonialista fue refrescante para muchos de nosotros, y el programa para descolonizar nuestros modos de pensar sobre el Otro transformó la disciplina. La bella ironía es que, justamente por causa de su especialización en el estudio del Otro, la voz peculiar de la antropología puede ser importante si es levantada contra el lado oscuro del exceso colonial. La antropología entiende la importancia de lo particular, y por lo tanto, de lo local sobre, y con contraste con, lo universal y lo global.

La retórica post-colonia ha sido estimulante y revigorizante para nuestro trabajo. La principal moción ha sido: ¿Dónde están las personas? ¡Por favor, déjenos ver y oír a las personas! Daré algunos ejemplos, tanto de dentro como de fuera de la antropología.

Cada vez más, los investigadores están trabajando en las interfaces de las disciplinas y métodos, juntando los conceptos y procedimientos de la filosofía, la lingüística, la antropología, la psicología, la poética y la historia. Michel de Certeau es uno de ellos. En People in the Plural (Gente en el Plural) (1977), la primera sección 
de su primer capítulo se titula "Contra la inconciencia". En La práctica de la vida diaria (1984), el autor subraya la importancia de llevar a cabo estudios sobre las prácticas cotidianas, como las artes de la cocina y la fina arte de la convivencia. De esta manera, los significados son encontrados en las artes de lo cotidiano, en sus estrategias, poéticas y artificios. Como afirma de Certeau (1984:6): debemos romper las fronteras rígidas de la empresa científica que transforma los modos de vida de las personas vivas y repletas de experiencia en meras sobras y notas de rodapié.

En un artículo notable llamado "La poética y el recentramiento de la antropología" (1991:40-42), Roy Wagner denuncia la política de la duda escondida en el juego de Descartes. Wagner ataca la "ciencia objetiva post-cartesiana", observando que ese mundo es una civilización de substitutos blandos, de realidades humanas gradualmente barateadas hasta la muerte, cuyos grados son medidos por esos comerciantes a los que llamamos de profesionales (es decir, antropólogos).

Ivan Brady (1991) constata con alivio que la antropología está redescubriendo su base poética para volverse nuevamente la "ciencia ingeniosa". Sugiere que estamos en la hora de rescatar lo que fue amontonado en el suelo del laboratorio del científico iluminista", para captar la astuta cultura de la realidaid comú" (ibid:8), un nivel de existencia que ha sido ignorado, trivializado o censurado por el presupuesto analítico que iguala toda (o la única "verdadera") realidad a sus concepciones y conclusiones" (ibid:9). Es necesario evitar el peligro de quedarnos eternamente inmóviles sobre los hechos en nombre de la "neutralidad analítica"(Brady, ibid: 22; Marien 1988). Brady ataca la mentalidad "bala de plata" - que busca un "tiro único", monolítico, que lo explicaría todo.

También está la contracultura filosófica a la que se debe de prestar atención: Feyerabend (1975), MacIntyre (1985), Taylor (1985), Toulmin (1990), Hesse (1994), Goodman (1968,1978), Baier (1994), y los científicos políticos como Benhabib (1992), todos trabajando sobre los descentramientos críticos de las grandes narraciones sobre la Sociedad, contraproducentes al éxito creativo de la Ciencia.

Homi Bhabha (Location of Culture, Ubicación de la Cultura, 1994), más abiertamente político, revindica el desarrollo de una literatura de "empoderamiento propio", el desarrollo de una literatura de reconocimiento por medio de la cual los pueblos marginalizados del mundo podrían descubrir sus propias voces. Estos son escritos que podrían tener un impacto revisionista sobre las relaciones tradicionales de dominación cultural desestabilizante. De esta manera, los que han sidoclasificados por la civilización occidental como más allá del muro del occidente podrían llevar a cabo de manera propia el trabajo de traducir quienes son. Podrían expresar su disgusto por las alegaciones progresistas del pensamiento oficial. Hay mucho que ganar con este nuevo discurso cultural que está siendo solicitado por los marginalizados del mundo (ver de Certeau 1997) 
Zygmunt Bauman juzga que la meta más difícil de alcanzar, especialmente en el mundo académico, es la superación de las técnicas radicales de desigualdad de los modernos (el punto de partida axiomático en gran parte de los argumentos sobre la superioridad de occidente) y de su programa para invisibilizar las diferencias. En Life in Fragments (Vida en fragmentos) (1995:166-7), el autor observa que "la modernidad era la época de las cruzadas culturales, la guerra sin piedad contra el preconcepto y la superstición... y la 'mano muerta' de la tradición". La modernidad descalificó y desarraigó todas las autoridades particularizantes, que fueron vistas como impedimentos en el camino del sueño modernista de la homogeneidad humana: el sueño de un mundo poblado de "seres uniformemente perfectos", únicamente alcanzado por los dictámenes de la razón.

Debemos regresar una vez más a la instancia del antropólogo moderno, porque todavía no nos dejó. Acuérdense que el legado de la teoría sociológica, coloca toda la riqueza de vivir y de la vida cotidiana, la estética y la poética, fuera de las fronteras de la sociedad, como perteneciente a dominios (irracionales) más allá de los límites de lo sociológico.

En verdad, la crítica post-colonial cambió profundamente a la antropología, como podemos constatar en el maravilloso conjunto etnográfico y retórico producido por la disciplina durante los últimos 10 a 15 años. Hay la idea de la emergencia dialógica de la cultura (Tedlock y Mannheim, 1995), y del acento sobre la noción de "culturamiento" (por muchos de nosotros). Hay un renovado énfasis sobre las prácticas en el mundo, y sobre su relación continua con conceptos (conscientes) (Ingold. 2000). Hay el desarrollo de una antropología de la conciencia y lo cotidiano (Brady. 1991; Wagner, 1991; Fabian. 1998;). Hay la insistencia sobre el papel crucial de la etnografía del habla en nuestros estudios etnográficos (la sabiduría de Dell Hymes). Hay el ataque continuo y focalizado contra las teorías representacionales del significado. Por ahora, las grandes abstracciones y los universalismos están pasando dificultades. Existe una rica etnografía, con estudiosos conversando entre sí y compartiendo experiencias. Las personas pueden ser realmente interesantes, con verrugas y todo (piensen en esa poética obscena de la descripción hecha por Kulick (1992) de la falta de mujeres en una aldea de Nueva Guinea). Hemos redescubierto el hecho que las personas tienden a ser (abiertamente, concientemente y súper-entendidamente) creativas de una multiplicidad de maneras fascinantes.

Obviamente, estábamos necesitando nuevas visiones de lo "sociológico", una ampliación y extensión de la empresa antropológica más allá de las estrechas fronteras y los intereses de la teoría modernista de lo sociológico.

Los modos de vida "sociológicamente" inciertos de los pueblos de la amazonía, se han vuelto más accesibles dentro de esta nueva sociología del conocimiento, que vuelve a permitir la entrada de la estética y la poética. Por medio de las narraciones y las visiones amazónicas de lo social, podemos comenzar a reconocer las 
repercusiones sociológicas del lazo íntimo entre sus prácticas cotidianas y su juicio estético. Podemos comenzar a comprender por qué para ellos, la belleza en la vida práctica (por ejemplo, en el arte culinario o en sus modos de inter-subjetividad) es una expresión de su valor político y moral.

Podemos comenzar a entender la relación entre la estética y la socialidad, entre la poética y la política, en los modos de pensamiento amerindios. Ahora podemos hablar de la "libertad" como una cuestión política para los amerindios. Establecemos relaciones con los pueblos indígenas del mundo de la manera como ellos son aquí y ahora, y no como una categoría ficticia de "primitivismo" de nuestro propio pasado.

Sin embargo, todavía tenemos mucho bagaje que botar - todas esas autoevaluaciones de la teoría modernista, en que se presupone que somos solamente nosotros, los modernos, los que poseemos los medios de sustentar las doctrinas conscientes del igualitarismo y el individualismo. Creemos con sinceridad, que son esas doctrinas las únicas que nos definen política y socialmente como "modernos". Como ya constaté, los antropólogos han tenido muchas dificultades en encontrar cualquier tipo de orden político y social entre los pueblos amazónicos. Yo misma, y varios colegas, esperamos que por medio de una antropología de lo cotidiano, nos aproximaremos a una comprensión de unà socialidad y un orden político en que las virtudes morales y estéticas de las relaciones interpersonales sean una preocupación mayor. Tal vez, al final, lleguemos a una estética comparativa, a una filosofía moral y una psicología social a través de las cuales podemos sostener interesantes conversaciones con los pueblos de la amazonía. Este sería un sueño.

Vamos a olvidarnos, por el momento, de la ciencia de la alteridad, y en cambio, intentar establecer esas conversaciones interesantes sobre la libertad y la autonomía personal, sobre la violencia del poder, y también sobre su creatividad. Sobre tipos de colectividades que pueden y han sido creadas por otros medios de lo que nosotros, los modernos, conocemos mejor.

¿Cómo proceder para entender las formas amazónicas de igualitarismo? Los pueblos amazónicos son altamente conscientes de estas cuestiones políticas. Ciertamente, lo son los piaroa, un pueblo de la cuenca del Orinoco con quienes estudié y conversé horas seguidas sobre estas cuestiories. Ellos valoran muchísimo la autonomía personal y también están fuertemente alados a sus modos colectivos de llevar a cabo las cosas. Para ellos, todas las relaciones sociales son personales e informales, fundamentadas en una buena dosis de convivialidad y también en la confianza personal, valores que frecuentemente son enfatizados por otros pr:eblos de la amazonía (ver Overing \& Passes 2003). La colectividad presupone la creación exitosa de relaciones de mutualidad estéticamente agradables. Ellos entienden que es difícil alcanzar dicho estado social, pero el intentarlo es, para ellos, una cuestión política. Como ven, no tengo ninguna hesitación en hablar de la filosofía política de los piaroa. 
Estamos comenzando a ver un tema común con respecto al orden político amazónico. Oliveira (2003) presenta una idea parecida sobre los mebenkogre (kayapó): el orden político emerge por medio de la creación, en el contexto ritual, de una intersubjetividad personalizada, constituida por individuos que exigen libertad. Estamos comenzando a llegar a un punto común de preguntas a las que debemos responder. ¿Por qué los pueblos amazónicos tienen tal rechazo por la jerarquía institucionalizada? ¿Por qué muchos de ellos consideran que la mera sugerencia de un comportamiento coercitivo es muy peligrosa? ¿Por otro lado, por qué tantos pueblos amazónicos hablan insistentemente sobre la creación de gente "buena/ bonita", que pueda vivir una vida sociable tranquila en común (Overing 1989; Overing \& Passes 2000?). ¿Por qué los pueblos amazónicos le dan un tan alto valor al sentido del humor, al bienestar afectivo y a la mutualidad sociable en sus prácticas diarias de convivencia comunitaria? ¿Por qué, también, hablan extensivamente sobre las dificultades y los peligros presentes en los procesos para alcanzar esta meta? ¿Cómo es que llegan al arte de la convivencia? Todas estas son preguntas amazónicas, levantadas por ellos mismos como temas de reflexión constante. Como tal, tienen valor político, y nos dicen mucho sobre sus propias distinciones de valor. Pero para comprender los por qué y para qué de estas preguntas - por ejemplo, desde el punto de vista piaroa, o yanomami, o kayapó - se necesita saber mucho más sobre el fundamento cósmico de estas preocupaciones, y las narraciones míticas por medio de las cuales el cosmos se revela. Hablaré brevemente sobre el fundamento cósmico de la visión piaroa.

\section{La poética y la política: el género de lo grotesco en la narrativa mítica.}

Es políticamente importante que el género de lo grotesco sea tan evidente en las narraciones piaroa en el plano mítico.

Ya he escrito un artículo (2000) sobre el importante papel de lo lúdico en las prácticas cotidianas piaroa, para quienes el sentido del humor, incluyendo las payasadas, las bromas, los juegos de palabras y hasta las obscenidades, es constitutivo de las actividades sociales diarias, como el trabajo en la chacra, la recolección y la preparación de alimentos. También es bastante evidente en las narraciones y en los rituales de los chamanes-líderes, que son unos grandes maestros de una elaborada retórica cómica de lo lúdico. El líder piaroa es antes que nada un bromista experto y, hasta cierto punto, un malandrín, que le enseña a los demás la necesidad social de aprender el arte de lo lúdico para lubricar los engranajes de la convivialidad.

¿Cuales son las repercusiones de este énfasis social puesto sobre lo lúdico? Según la visión indígena, la folía juega un papel significativo para lograr una

En el texto original, la palabra utilizada es "folly". Hay muchas posibilidades de traducción de esta expresión, entre las cuales "locura", "tonteria" y "bobada". Resolvemos mantener "folia", en el sentido de "broma", "confusión”, "jolgorio", "fiesta”, "entretenimiento", dado el carácter neutro, que se aproxima más a la idea que está siendo presentada. 
socialidad cómoda, informada y por lo tanto, exitosa. Será conveniente hablar, así como lo hace Peter Berger (1997) sobre lo cómico como un modo de conocimiento. $Y$, así como este autor, tal vez nosotros también podríamos llegar a comprender y valorar a los pueblos cuyo modo de vida reconoce la "visión cómica del mundo". Debido a la predominancia de esta visión de mundo entre los pueblos amazónicos, los etnógrafos debemos entender su capacidad de poder ampliar nuestra comprensión.

En otros trabajos recientes (Overing 2003, 2004), he explorado la relación entre la socialidad lúdica de los piaroa y los géneros de sus relatos míticos (el acto de narrar - performance - como un acontecimiento cotidiano). Hay una poética en la narración de los mitos que está vinculada a las percepciones cósmicas y morales, y que también opera un desdoblamiento de modos de ser en el mundo (ver Hymes 1981 y Vernant 2002 - el acercamiento poético de estos autores a los amerindios y los antiguos griegos, respectivamente, adelantan mucho la descolonización de la intelectualidad). Esta poética, con su género obsceno y estridente de lo grotesco, se encuadra en una elaborada filosofía de la folía. Sostengo que por medio de esta filosofía podemos entender la actitud política de los piaroa, y de su socialidad.

Los relatos míticos muestran una preocupación con las repercusiones sobre la condición lummana de los extraordinarios modos de poder liberados en el tiempo mítico para permitir la vida en la tierra. El tiempo mítico remite al momento en que el paisaje que vemos hoy en día en la tierra se desdobló lentamente por medio de la brujería y las artimañas de los poderosos dioses creadores. Estos poderes de los dioses, que eran lo suficientemente fuertes como para llevar a cabo toda la creación, eran también salvajes, violentos, venenosos (la comparación con los mitos de la Grecia antigua es adecuada). Es muy placentero sentir y experimentar un relato mítico siendo narrado, porque el acto narrativo tiene mucha folia y trama, tremendamente graciosas y también obscenas.

En los relatos, hay bromas locas y transformaciones interesantes (invertir la cabeza y las nalgas del armadillo; agarrar un pene volando en el aire para llevar a cabo la creación de los hombres; el día en que los seres humanos perdieron sus brillantes anos azules). También están las batallas de los dioses, con sus trampas engañosas y los efectos inesperados de sus intenciones. Más seriamente, los dioses también se atacan con juegos de fuerza de locura, una forma de paranoia que les da ilusiones de grandeza, los deja locos, los hace matar a su propia abuela. El tiempo de la creación, parecido al ciclo de Edipo de Sófocles, se mueve desde una especie de ironía malvada hasta el lugar más oscuro y grotesco de la tragedia de hybris². Fue durante el tiempo de la creación que la folía realmente se extravió. Este tiempo

Hybris: concepto griego de orgullo, arrogancia, auto-confianza excesiva, que también significa las formas violentas y libertinas de actuar derivadas de la insolencia de la presunción de las vanidades excesivas. 
se desdobla en un universo ridículo y vengativo, por lo que para entender mejor el final del tiempo de la creación, hay que verlo como constituido por un paisaje de monstruos vivamente colorido. Lo cual no es de sorprenderse, puesto que el padre de todos los alimentos cultivados, el creador de las poderosas artes culinarias y de todas las potentes fuerzas que permitieron la agricultura, la cacería, el curare, el fuego de cocina, también era un loco tiránico y grotesco. Su nombre es Kuemoi, y es retratado como un bufón diabólico, que se ríe locamente con cada una de las intrigas que crea, gritando de rabia cuando no acierta, entrando en pataletas cuando encuentra impedimentos, en fin, una figura de la alta comedia, no de tragedia. Cuando es vencido por la locura total, corre dando vueltas en círculos sin fin (lo que me hace recordar la descripción que Robert Nye hace del diablo en Merlín: "Sonríe irónicamente como un zorro comiendo mierda de una escoba de alambre; el diablo "ronca tan alto como un puerco"; se carcajea y se retuerce". El lado ridículo, absurdo y gracioso de la maldad).

Ese dios creador de las maneras de comer civilizadamente era el dueño de lo que los piaroa llaman las "cajas de cristal de la tiranía, la traición y la dominación". Kuemoi soltó todos esos horrores de sus cajas de poderes primordiales, impactando de lleno a este mundo. Era el dueño de las cajas de cristal de la noche; fue quien, con gran alegría, soltó la noche y todas sus criaturas peligrosas en el espacio terrestre. Todos estos seres odiosos eran sus armas. De hecho, todas su creaciones le sirven de armamento, inclusive las artes culinarias. Todas tienen poderes para matar o envenenar. Durante sus escapadas, Kuemoi se transformó en jaguar, buitre, bagre, y serpiente - bajo esta forma, adquirió las ropas de la fuerza física. Era un personaje pequeño pero monstruoso y de dos cabezas, una para comer carne cruda y otra para comer carne cocida. Kuemoi es la figura arquetípicamente mala del tiempo de la creación, y la más ridícula.

Este dios muy bobo que tiene todo el conocimiento de las artes culinarias remite a una teoría altamente sofisticada del comportamiento ético y (según la percepción piaroa) a la potencialidad que tienen todos los seres humanos de comportarse de manera odiosa y malvada. Una crueldad profunda lo motiva, a él y al uso de su fuerza. El poder de sus pensamientos de brujería, provenientes de los alucinógenos venenosos que tomaba (del óxido del sol, de las plumas del sol), suficientemente poderosos como para crear las artes culinarias, envenenaron a su voluntad. Vencido por la locura total, Kuemoi siempre actuaba sin razón. No tenía dignidad. El mal está claramente asociado al conocimiento (al exceso de poder) y Kuemoi, claramente, tenía un exceso de ambos. También experimentó un envenenamiento de sus emociones (la enfermedad que los piaroa llaman ke'raeu - paranoia, hybris, o deseo de matar). Esta condición de sufrir de un conocimiento venenoso incontrolado está firmemente vinculada al imaginario de la locura y la bufonería.

Al final del tiempo de la creación, todos los dioses y los otros seres habían sido desrumbados por esta enfermedad de la paranoia, la enfermedad de comer 
civilizadamente, la enfermedad de girar y caer. De ahí en adelante, el paisaje terrestre del tiempo de la creación decayó en lo grotesco y la violencia caótica, hasta volverse un mundo donde la hybris reinaba. Una comunidad se volteó contra la otra: se devoraron unas a otras como animales, transformándose en las fuerzas jaguar de kuemoi.

Este holocausto caníbal se terminó cuando una diosa llamada Checheru, la hermana promiscua del dios creador de los seres humanos, la madre de los perfumes y de la locura de la orina de mono, juntó todas las fuerzas mortíferas de las artes culinarias de Kuemoi y se las llevó a un lugar seguro en el espacio celeste, por encima de las montañas, donde aún se encuentran hoy en día, trancadas dentro de las cajas de útero de cristal, de donde se habían originado. Hoy en día, los chamanes piaroa pueden tomar estos poderes terribles/maravillosos, pero solamente de a pocos, para dárselos a cada uno de los miembros de su comunidad.

El punto crítico es que el paisaje monstruoso del tiempo de la creación está siempre interactuando con cada una de las prácticas emprendidas por los piaroa en el tiempo cotidiano. Las creaciones locas de los dioses establecieron todas las posibilidades de ser en este mundo, de actuar y de existir en él. Las prácticas de los dioses creadores también establecieron todas las condiciones para relacionarse dentro de un mundo y entre los mundos del "multiverso" "al que los piaroa pertenecen. Cabe anotar el hecho que a lo largo del tiempo de la creación, las prácticas de los dioses creadores se volvieron progresivamente más y más grotescas. Este hecho llevó a los relatos míticos a su punto final. Las artes de las habilidades culinarias, que en su debido tiempo se convirtieron en la condición humana, incluían los modos de poder - las prácticas - las más peligrosas. Podían generar un tirano. Podían llevarnos al asesinato.

\section{El juego de las prácticas diarias y los géneros de lo grotesco}

La vida diaria en una comunidad piaroa me pareció muy cómoda, fácil de llevar y segura. Los niños jugaban libremente. Los esposos y las esposas planeaban juntos las actividades del día. Por la tarde, los adultos y los niños que regresaban al poblado de cazar y recolectar en el bosque, o de cosechar en la chacra, eran recibidos con entusiasmo por todos los que se habían quedado atrás. En la gran casa comunal, las mujeres descansaban, conversando pelando yuca. Cerca de ahí, los hombres confeccionaban dardos, tejían cestos, participando en las bromas de las mujeres. Los hombres y las mujeres se divertían juntos, contándose las experiencias graciosas de ese día - en las chacras, en el bosque. Las abuelas y las muchachas jóvenes

Adoptamos el neologismo "multiverso", del inglés "Multiverse", propuesto por la autora en contraposición a la noción de "universc, manteniéndose de este modo el sentido de la multiplicidad de los "mundos" tal y como es el caso entre los pueblos amazónicos, incluyendo a los piaroa. 
regresaban a la plaza del poblado con leña y agua. Flameantes muchachos jugaban badmington, utilizando sus manos para lanzarse una mazorca de maíz. Los baños diarios en la quebrada fría, un pequeño afluente del Orinoco. Comidas conviviales compartidas. Bromas y chistes abiertos. Cuando llegaban visitantes, eran saludados alegremente, cuidados y bien alimentados.

Me tomó un buen tiempo establecer una relación entre esta tranquilidad y las imágenes absurdas de las narraciones chamánicas. A menudo la gente me hablaba de estas conexiones, claramente eran complejas, con muchas capas de significados -y a menudo muy sorprendentes. Pero, empezar a comprender su significado, fue otro asunto. La vida social, cultural y política de una comunidad como ésta resulta ser mucho más colorida, excitante, interesante - y ciertamente más intelectual - de lo que un ojo inocente podría detectar. La tranquilidad que observaba era un sano espíritu de comunidad cuidadosamente trabajado, ganado a duras penas, que nos habla de un igualitarismo muy ajeno a la imaginación occidental moderna. Había una libertad tremenda en la manera piaroa de vivir ¡Pero no era una libertad fácilmente comprendida por nosotros, académicos occidentales! Poco a poco las imágenes de una maravillosa historia de misterio (intelectual) se fueron mostrando ante mi: lentamente las piezas extraordinarias se fuero juntando.

Primero, estaban los ruivatu, o líderes chamánicos. Eran hábiles magos, guerreros del espacio, doctores, sicólogos, profesores de nido de infancia, docentes, filósofos, cosmólogos, actores de comedia, poetas laureados y agrónomos. Eran responsables por la fertilidad de su pueblo, y también por el uso de la tierra. Su poder era grande y su inteligencia tremenda.

Mi primera noche, la pasé en la gran casa comunal de un poderoso ruiva, en una pequeña quebrada del Orinoco llamada Paria Chiquito. Fue, a la vez, impresionante y aterrador. Mi esposo y yo habíamos sido recibidos en la comunidad de Maparæeku, nuestras hamacas tendidas alrededor del círculo de hogueras para dormir. Fuimos invitados a cenar, y después nos preparam.os a dormir. ¡O más bien, eso pensé! Estábamos exhaustos después de caminar durante dos días por las colinas de la Guyana, entonces me quedé dormida de irmediato. Pero me despertaron unos sonidos extraños. Algún tipo de canto ritual estaba siendo llevado a cabo, y no tenía ni la menor idea de qué significaua. ¿Sería q: e estábamos en peligro? ¿Sería que estaba dirigido a nosotros, los extranjeros? Miré en la oscuridad y vi que todos los hombres de la comunidad habían colgado sus hamacas cerca de la hoguera de Carlos y Camila, los líderes masculinos y femeninos de la comunidad, que eran.llamados, respectivamente, de ruwa y ruwahu (nunca supe sus nombres originales, ya que esto hubiera sido un terrible insulto para ellos. ¡Después me informaron que usar el nombre de una persona cuando esta tiene más de cinco años era algo así como mostrar sus genitales en público!). Escu:ché cuidadosamente los sonidos que venían de la

\footnotetext{
Myron Kaplan
} 
hoguera, y percibí un padrón. Carlos cantaba por un tiempo, de una manera nasal y no muy melódica, y los hombres le respondían en coro. Me tranquilicé. Que sea lo que tenga que ser ... en la mañana, mi esposo y yo nos despertamos en la seguridad de nuestras hamacas. ¡En el suelo, entre nosotros, había una piña! - un dulce que la mujer más anciana y su nieta nos habían traído. Había una piña en cada hoguera de la casa. En cuanto al canto, este continuó cada noche - de cuatro a cinco horas por noche - por el resto de nuestra estadía de un año en Maparæku.

Estos cantos resultaron ser inmensamente importantes en las prácticas piaroa del día a día. ¡Treinta y cinco años después, todavía estoy intentando comprenderlos! Durante nuestro primer trabajo de campo, conseguí aprender lo básico de su sentido. Para el ruiua, cantar es una manera de tratar la salud y la fertilidad de los miembros de su comunidad. Les brinda protección, haciéndole la Guerra a los grandes depredadores de la noche que les podrían hacer daño. El ruiva canta para hacer que la comida se vuelva segura de comer, y para esto transforma a los animales que los cazadores quieren matar al día siguiente en alimentos vegetales que no conllevan peligro. ¡Bromeando, los Piaroa me dijeron que por eso eran vegetarianos! El ruiva también canta para asegurar el bienestar diz las mujeres embarazadas durante el parto, y prevenir que el pene primordial del Padre de los Animales debajo de la tierra impregne de noche a las mujeres con su semen monstruoso. Para proteger y curar a los suyos, el canto del ruiva er.vía al 'dueño de los pensamientos' (ta'kivaruiung) a viajar por los muchos mundos del multiverso $0^{5}$ piaora, hasta encontrar a los antiguos de los tiempos de la creación que están causando tal o cual enfermedad en una persona de la comunidad. Envía al 'dueño de sus pensamientos' Tak'waritun, (su espíritu personal que cuida de su 'vida de los pensamientos' y de su 'vida de los sentidos') ${ }^{6}$ a las casas de los dioses actuales, para pedirles que lo ayuden en su batalla contra la enfermedad. Los dioses pueden entonces convertirse en grandes fuerzas depredadoras, como un jaguar o un oso de anteojos, y dejar sus casas en el cielo para ir a devorar a las fuerzas de enfermedad que se han metido en el cuerpo de la persona enferma. Los cantos del ruiva despliegan la cosmología, la historia del universo, la historia de la creación de los espacios terrestres, y todo lo que contienen. Cuentan sobre los otros mundos que pueden afectar adversamente, vengativamente, a los piraroa durante sus rutinas diarias. Cada noche, el ruiva sopla todas las palabras de su canto dentro de un recipiente con agua, y otro con miel (para los niños), que todos los miembros de la comunidad toman al día siguiente para incorporar la potencia protectora de lass palabras de los cantos en sus cuerpos.

5 Ver Overing (2004) sobre los 'mitopaisajes' del 'multiverso' piaroa.

- Ver Ov zring 1985b sobre el tema de ta'kivaru'w', y su relación con la teoría piaroa de la mente que enfatiza el juego reciproco entre la intencionalidad, la 'vida de los pensamientos' y la 'vida de los sentidos' (o dicho de otra manera, el juego reciproco entre la mente, la voluntad y ei deseo). 
Yo me preguntaba sobre los por qués y los dóndes de este multiverso malevolente piaroa, y sobre su relación con lo que significa vivir una vida social humana, una existencia igualitaria y segura. ¿Y qué pensar del ruwa-y su esposa, la ruwoahu? Él, el que tiene fuerzas para viajar por el multiverso; ella, la creadora de grandes y hermosas chacras. ${ }^{7}$ ¿Cómo se relacionaban al estilo de vida igualitario?

Antes de nuestra llegada a Maparæku en 1968, mi esposo y yo viajamos por los afluentes del Orinoco para conocer a otros poblados piaroa donde vivir. En un cierto momento, estábamos viajando en canoa, con un buen guía Guahibo, por un afluente del río Sipapo. Nos acababan de avisar sobre una comunidad interesante río arriba. No habíamos vistos signos de existencia humana durante todo el día, después de pasar la noche en unas rocas debajo de una lluvia torrencial. Finalmente llegamos al atardecer, a un gran poblado. Vimos tres casas comunales llenas de gente. Habían por lo menos trescientas personas. Junto con nosotros, llegó un grupo de hombres que regresaban de la cacería, trayendo por lo menos treinta huanganas en sus espaldas. Habíamos llegado en medio de un Sari festival, la gran ceremonia de 'aumento' de la fertilidad que los piaroa organizan, si pueden, cada año. Cuando bajamos en la orilla, fuimos saludados por un hombre pequeño y sonriente, que fue nuestro anfitrión durante nuestra estadía. Nos mostró el lugar, llevándonos a la casa comunal donde todas las mujeres estaban preparando comida, y hacienda chicha. Nos hizo sentar y comenzó a enseñarnos algunas frases en piaroa. La primera palabra que aprendimos fue adi'wo, que quiere decir 'bueno', 'bonito'. Nos explicó que éramos gente adi'wa, y que yo era adi'wuahu, la forma femenina. Desde el principio, nos hizo sentir seguros y contentos, y nos dio un plato de hígado de huangana cocido. Después nos enseñó donde dormir cómodamente, y al día siguiente nos despidió, invitándonos a regresar para vivir con ellos por un tiempo.

¿Quién era este gentil hombre? Tengo que admitir que pensamos que era un anciano gracioso que no tenía utilidad en los procedimientos ceremoniales, y que podía perder su tiempo con nosotros. Bueno, pues luego supimos que este hombre adorable era el ruwa, el gran y poderoso líder ceremonial y dueño de este festival espectacular que duraba un mes. La mayoría de los que estaban ahí eran sus invitados de las comunidades vecinas. El Sari es el ritual más peligroso realizado por los ruivatu. Es la ceremonia de fertilidad, de 'aumento', de multiplicación, gracias a la cual la selva se llena de presas de cacería. Este ancianito era el responsable por toda la producción del Sari, incluyendo la protección de todos los participantes para que no sean atacados por los espíritus de los muertos gritando, que ansían estar junto a sus parientes vivos y quieren robárselos para llevárselos a la 'tierra de los muertos'. También quieren robarse a la hermosa música del Sari festival. Es el festival en el que el ruiva ceremonial inicia a los jóvenes varones en la casa ceremonial: les

Ver Serena Heckler (2004) sobre los poderosos cultivadores (rutvahu) piaroa de la actualidad, que son claramente iguales a las 'grandes mujeres' de los 1960's. 
administra sus primeros rituales para que obtengan habilidades de cacería. Este festival termina en un gran momento ritual en el que todos los adultos son golpeados (ligeramente) debido a su culpa por haber consumido carne de cacería, lo cual es considerado ipso facto un acto de canibalismo: todos los animales del bosque fueron alguna vez seres humanos, y siguen siéndolo en los otros mundos del multiverso. Este anciano era el líder chamán más poderoso de la tierra piaroa. En este festival, él transformó a los humanos que vivían debajo de la tierra en animales de cacería para que sean comidos por su gente. Le dio a los jóvenes varones las fuerzas de pensamientos de las cajas útero de cristal de la diosa Chehehu para que pudieran, por medio de ellos, cazar a sus animales.

¿Por qué las personas más poderosas entre los piaroa también son las personas con la actitud más humilde? Cada poderoso ruwa que conocimos, se presentó ante nosotros de la misma manera: alegre y bromista, vestido simplemente, con gracia respetuosa, anfitrión generoso. También me explicaron que todos los hombres son ruivatu, y todas las mujeres ruivahu, porque todos han recibido las fuerzas de pensamientos de los actuales dioses Timnazua para controlar las habilidades necesarias para el uso diario de las artes culinarias y la vida social apropiadas a su género. Desde la infancia, el ruiva les da instrucción formal sobre las habilidades de la convivencia ${ }^{8}$. Cuando las muchachas menstrúan por primera vez, atraviesan un ritual junto con el ruwua, por medio del cual reciben las fuerzas de pensamientos de las cajas útero de cristal de los dioses que les permiten controlar su propia fertilidad, ${ }^{9} \mathrm{y}$ por lo tanto, ser responsables por el nacimiento de sus hijos. Cuando los muchachos llegan a los doce años, reciben ritualmente las fuerzas de pensamiento para convertirse en excelentes cazadores y pescadores. Esas 'lecciones' pueden continuar, si la persona lo desea, hasta más tarde durante su vida: las capacidades siempre son un asunto relativo, y en gran parte, son escogidas por las personas. Solamente unas cuantas personas tienen la inteligencia y el deseo de atravesar las penurias necesarias para convertirse en grandes ruivatu o ruivahutu. Sin embargo, como Jesús, el hijo mayor de dieciocho años de Carlos me explicó entre bromas: "¡Yo también soy un ruiva:"! Sorprendida, en gran parte debido a que él era generalmente muy humilde con respecto al conocimiento chamánico, le pregunté, ¿cómo así? "Bueno", me contestó, «iSoy el ruwa de mi hamaca, el ruiva de mi pene»! Básicamente, lo que me decía era que, por cierto, él era el dueño (responsable) de su propia sexualidad. Al principio no lo comprendí, pensando que solamente estaba bromeando. Sus palabras cobraron más sentido con el siguiente relato sobre los tiempos míticos,

$8 \quad$ Ver los artículos en Overing \& Passes 2000 (eds.) para ejemplos de pueblos amazónicos que valoran el arte de la convivencia, y que también son altamente reflexivos sobre las dificultades de lograr dicha convivencia.

$9 \quad$ Los piaroa me dijeron que antes, los ruzvatu sabían los cantos para evitar embarazos, Me explicaron que habían perdido ese conocimiento. Sin embargo, después del ritual para su primera menstruación, la muchacha es considerada como responsable por su propia fertilidad: ella escoge cuándo embarazarse y de quién. 
frecuentemente incluido en los cantos nocturnos de los ruivatu, especialmente, en las casas comunales donde habían muchos adolescentes. Es uno de los relatos favoritos de este grupo de edad, y les encantan contarlo. Trata sobre ei día en que los piaroa perdieron sus brillantes anos y genitales de color azul cristal A mí también me gustó este episodio. La historia, una versión contada en 1977 por un hombre, cuyo nombre también era Jesús, dice lo siguiente:

\section{Los piaroa perdieron sus brillantes anos azules}

Paruna (el dios creador de los bienes de la grente, y esposo de Cheheru) no podía encontrar plantas alucinógenas y/opo (Banisteriopsis) cerca de su casa, entonces se fue de viaje a Caracas para buscarlas. Durante ese tiempo, Wahari (el dios creador de la gente, y hermano mellizo de Cheheru) decidió visitar la casa de Paruna y su hermana. Tampoco no podía encontrar plantas de yopo en su propia casa, y pensó que podría obtenerla en casa de su cuñado. Para conseguirla, Wahari copuló con su hermana Cheheru. Y, de esta unión con Wahari, Cheheru sacó una planta de yopo de su propia vagina y se la dió a su hermano. Mientras tanto, Paruna, todavía de visita en Caracas, estaba observando lo que sucedía en su casa por medio de la fuerza de sus pensamientos: y vio que Wahari estaba tranquilamente moliendo yopo - iy que a su lado Cheheru estaba acostada desnuda en su hamaca! ¡Paruna sabía que no había yopo en su casa! Furioso, Paruna regresó apurado para exigirle a Wahari que le contase donde había encontrado ese yopo. El arrogante Wahari le contestó, como si nada, que crecía cerca a la casa de Paruma. ¿No lo había visto? Los dos cuñados comenzaron a discutir a causa del incesto de Wahari con Cheleru, sin poder parar. Todavía siguen discutiendo hasta el día de hoy, en los confines de la tierra. Fue en ese momento, en el instante en que la querella comenzó entre Paruna y Wahari, que los piaroa perdieron sus brillantes anos y genitales de color azul cristal. Desde que perdieron su brillo colorido, los piaroa han podido ordenar su propia sexualidad por medio de sus pensamientos en vez de por medio de sus anos.

Tanto los hombres como las mujeres deben reflexionar sobre las consecuencias de sus vidas sexuales. Los piaroa, de ambos géneros, valoran enormemente su derecho a la autonomía personal en todos los procesos de decisión. Cha'kuakomene! ('iEs mi manera de hacer las cosas!). Esta afirmación enfática de autonomía, o propósito, personal era a menudo proferida cuando alguien les hacía una pregunta sobre por qué hacían tal o tal cosa. La única 'regla' o 'restricción' que yo jamás haya visto a una persona piaroa admitir, es que un joven varón tiene que permanecer en la casa de la muchacha que ha embarazado - y quedarse ahí a lo largo de todo el embarazo. Para protegerla a ella y al feto, es necesario que todas las noches participe en el coro que responde al canto del ruiva. Si él no cumpliese sus obligaciones, y la muchacha o el feto se enfermasen - o peor aún, muriesen, el debería pagarle a los padres de ella una multa muy pesada. ¡Claramente, esto era un incentivo para pensar cuidadosamente antes de embarazar a alguien!: ser el ruion de su pene, y la rutunhu de su vagina, en vez de actuar de manera insensata por el ano - la vida de los sentidos. 
La autonomía personal es un concepto social, tal y como lo explican los piaroa: uno siempre debe tomar en consideración el efecto que nuestras propias acciones puedan tener sobre los demás. Uno no debe de hacer daño a los demás.

El control de su propia fertilidad es el punto crucial. Los locos dioses creadores nunca fueron capaces de manejar su fertilidad. Eran controlados por sus deseos salvajes, y su fertilidad residía en sus partes inferiores. Dominados por la arrogancia, nunca fueron capaces de dar a luz a una progenitura de manera normalmente humana. La mayoría de la fertilidad mítica es una folía terrible, por medio de defecaciones (diarrea), vómitos proyectiles, y violentas expulsiones de gases del cuerpo. Este es el gran contraste entre la monstruosa fertilidad de los dioses creadores y la fertilidad controlada que los piaroa entienden como la única manera de reproducirse propiamente humana, una fertilidad que es un asunto social. Fue al estudiar el lenguaje de los cantos de manera más intensa en 1977, gracias a las enseñanzas de los ruwatu de varias regiones de la tierra piaroa, y con la ayuda de interpretación dedicada de varios jóvenes piaroa, que adquirí un mejor conocimiento de la cosmología piaroa y de su violenta cosmogénesis - y por consecuencia, también de la socialidad piaroa ( $\mathrm{y}$ de las razones por las que colocan tanto énfasis sobre lograr una convivialidad buen humorada).

Llegué a prestarle especial atención al tema de las excreciones corporales, y de sus diferentes potencias fertilizantes. Para los piaroa, la creación fue llevada a cabo de tres maneras: intencionalmente benévola, intencionalmente malévola, o por inadvertencia. Ahora nos estamos acercando a la manera cómo los piaroa comprenden las conexiones entre los eventos grotescos de los tiempos de la creación (tal y como son desplegados en los cantos de los ruwatu) y los días actuales de la socialidad. El comportamiento del supremamente poderoso ruw Wa Wari, claramente, no era del tipo que podría engendrar relaciones familiares. ¡Arrogantemente, mandoneó a sus parientes, pensando en cómo matarlos! En cambio, dentro de la comunidad piaroa, es inaceptable que alguien le de órdenes a otro, y es especialmente indebido que un poderoso ruwa lo haga. El líder chamánico debe de mostrar preocupación por la salud de los miembros de su familia extensa. Desafortunadamente, la voluntad de Wahari se envenenó con todas las trampas tentadoras que el dios creador de las artes culinarias, Kuemoi, le puso. Perdiendo todo el sentido de la compasión por los demás, Wahari se volvió un compañero traidor. En lugar de hacer la vida placentera para los piaroa, tal como era su primera intención, por accidente (y luego, viciosamente) creó la mayoría de las penurias de esta vida - especialmente la mala salud, y los derrames de sangre por orificios inesperados o en momentos sorprendentes.

Los dardos de la pucuna de Wahari embarazaron perversamente a Tucán, cuya sangre derramada creó un abortó. La fertilidad de tipo mítico es notablemente asociada tanto a la violencia como a la perversidad, a la sexualidad desviada. $Y$, como mencionamos, la creación es a menudo unida a la defecación y la diarrea, o a 
la expulsión de sustancias de varios orificios del cuerpo - el ano, la vagina, y la boca: intentos fallidos de conseguir una creación más constructiva. En el canto sobre Tucán, se entiende que su vómito sangriento tiene poderes masculinos fertilizantes parecidos al semen. Como el curare proviene solamente de una fuente de fertilidad masculina, las presas de caza muertas con curare son peligrosas para las mujeres. De igual manera, la sangre menstrual y de post-parto, fuentes de fertilidad puramente femeninas, son peligrosas para los hombres.

Las plantas de curare a las que la sangre de Tucán dio nacimiento no son, sin embargo, la fuente de la resina que los piaroa utilizan hoy en día para hacer el veneno de cacería. Las 'plantas' de Tucán son, más bien, las enfermedades de los abortos, que son de por si, embarazos perversos. El intento de Wahari de crear un curare de cacería útil no sirvió de nada: en lugar de eso, creó una enfermedad terrible que él proclamó para el futuro de la gente. Y este escenario se repitió en todos sus intentos de crear sus propias artes culinarias. Los cantos que tratan sobre los intentos de Wahari de crear leña, anzuelos, arcos y flechas, curare, y todo lo demás, muestran que estos condujeron a los demás horrores que creó. Todas creaciones perversas, enfermedades horribles, gonorrea, parálisis, ceguera, hongos de la piel, quemaduras, dolores de garganta. La peor mala jugada de Wahari fue invitar a todos sus parientes de la selva a una gran fiesta. Anfitrión generoso, los emborrachó totalmente, y después comenzó a transformarlos en animales de cacería. Les quitó todos los pensamientos que les permitían utilizar las verdaderas, efectivas, artes culinarias para hacer chacra, cazar, pescar, y en su lugar les dio por "pensamientos" sus propias creaciones perversas, por medio de las cuales los animales de hoy pueden impregnar a la gente de la tierra piaroa con todas las enfermedades de las que sufren desde entonces. En represalia por su mal proceder, los propios parientes de Wahari lo cazaron como si fuese una presa de cacería en el bosque, y le dispararon a muerte.

En Maparæku, la primera cosa importante que aprendí de los cantos de Carlos fue que él estaba protegiendo nocturnamente a los miembros de su comunidad contra estas 'enfermedades de los animales'. Su hijo nos advirtió que debíamos tener cuidado de no caminar sobre la orina o los excrementos de los animales en la selva, porque era especialmente por medio de estas excretas que las enfermedades eran contagiadas a los seres humanos. Jesús explicó que el olor de estas excretas era un potente conducto de enfermedad, así como el olor de la sangre de los animales. Varias veces, me encontré con cazadores y sus esposas cuidadosamente desangrando en el río a los animales de cacería de gran tamaño, como una huangana, y limpiándola bien, preparándola para ser cortada de manera segura para comer.

Fue después que comprendí que según el pensamiento piaroa, existe una unión estrecha entre las excretas perversas de los tiempos de la creación, las excretas de los animales que traen enfermedades, y las excretas de los seres humanos. Estos tres tipos de excretas tienen poderes de impregnar perversamente a los demás. Fue gracias al tiempo pasado estudiando el canto de Jose Luis sobre el origen de la creación por 
Wahari del "curare" de Tucán que pude comprender que las excretas, en general, era poderosos medios de impregnar perversamente a los demás, y por lo tanto comprender que la enfermedad es un proceso de impregnación con un efecto inverso a la procreación. Dos jóvenes, Jesús y Antonio, trabajaron con entusiasmo con nosotros para comprender el lenguaje de este canto, y los matices de sus complejas metáforas. Para ayudarnos a comprender, solían bromear y hacer juegos de palabras, uno de sus pasatiempos preferidos de todos los días.

A Antonio y Jesús les gustaba indicarnos las conexiones existentes en su idioma sobre las excretas del cuerpo. Nos explicaron que todas las excretas del cuerpo son llamadas i'sæiva, pero, interesantemente, en el canto (sobre Tucán) defecar, vomitar y eyacular eran referidos por el mismo término: edéku - o edekiva'a, el mal olor resultante de todos estos procesos. Más extraño aún, nos dijeron que la palabra para un aborto, pui'kiva, también significa eyaculación. ¿Cuál sería la semejanza? Se me ocurrió, de manera tal vez obvia, que así como una mujer pierde el beneficio de una eyaculación fértil al tener un aborto, un hombre, al eyacular, también pierde su potencia, que se va al cuerpo de la mujer, y no se queda en su propio cuerpo. La potencia entonces se encuentra en ella. Antonio y Jesús, el canto sobre Tucán les hacía pensar en las bromas que los muchachos se suelen hacer cuando alguien se tira un pedo. Los pedos, entre los piaroa, así como otros pueblos amazónicos, dan mucha risa. Antonio y Jesús me dijeron que los 'pedos' en su idioma se llamaban "humo de mierdas" (tité iso' pha). Los muchachos tienen muchas bromas sobre suegros para contarlos cuando alguien se tira un pedo. Tienen un amplio vocabulario para expresar ideas como: ‘¡tu suegro está cagando’! o ‘está gritando!', o ‘iestá vomitando!' El que hace las bromas también puede decir algo como ‘jestás vomitando a tu suegro'!', refiriéndose a las drogas alucinógenas tomadas por los hombres causando vómito. Hacer comentarios como estos, es una diversión burlona, pero la intención por detrás va más allá y se trata de desearle buena salud al amigo que se tiró un pedo, algo así como la expresión en alemán 'gesundheit', cuando alguien estornuda. El suegro del muchacho es, por cierto, un hombre con mayor conocimiento que su yerno. Es un ruzva más poderoso. Como tal, sus excretas corporales - su sudor, su orina, la cera de sus orejas, sus excrementos, sus pedos - son peligrosos para la salud de los que viven con él y que tienen menos conocimiento. Al tirarse un pedo, el joven está librándose de la contaminación que su suegro le impartió. Su 'pedohumo' es, sin embargo, también un peligro para sus amigos, implicando la transferencia de dañinos poderes hacia ellos.

Una y otra vez, como Antonio y Jesús solían enfatizar, las evidencias apuntan hacia la sexualidad, la fertilidad, y la posible perversidad de todas las funciones corporales y las excretas del cuerpo. ${ }^{10}$ En las narraciones de los cantos, frecuentemente

Para discusiones sobre las sorprendentes asociaciones semánticas en el idioma piaroa sobre los peligros mutuos de los géneros, véase Overing 1986. 
se expresa el lado cómico de estos peligros. En el relato mítico cantado por Carlos y José Luis sobre la creación de la gente por Wahari, se dice que hizo los sesos de la gente con el pus de los chupos de sus enfermedades venéreas ( $i W a h a r i$ hasta nació dentro de las cajas de cristal de gonorrea de Tapir/Anaconda!). El nombre de esta caja de gonorrea, como Antonio y Jesús (2) nos informaron, es "viejo lujurioso" (unæsæyu). Los chupos llevan el mismo nombre, izvá maruiva, asi como las marcas faciales que expresan el conocimiento de la menstruación de una mujer. Esta pintura facial es llamada k'erảu, y está relacionada a las temidas paranoia y megalomanía, de las que Wahari sufre continuamente, y que causan su comportamiento tiránico. Los hombres y las mujeres son iguales en sus peligros - así como en sus utilidades el uno hacia el otro. Las excretas de cualquier adulto pueden ser peligrosas para los que viven con ellos, las más peligrosas siendo, por su puesto, las de un poderoso chamán-líder (quien, inevitablemente, también es un suegro).

Por otro lado, esta transferencia de poder entre la gente que vive junta es crucialmente procreativa en el sentido positivo. Según los piaroa, el recibir la vida es un proceso continuo y complejo. Se considera que un número de factores, actos, y acontecimientos, contribuyen a la creación de las fuerzas de vida propias de una persona. El acto de entregar conocimiento es un acto reproductivo: es el trabajo que procrea. A medida que la gente se va volviendo mas saludable, tanto mentalmente como físicamente, también se vuelve más conocedora y hábil en las artes culinarias: incorpora en sus cuerpos más y más de las 'fuerzas de pensamientos' (takivanya) creativas y fértiles de las cajas de cristal de los dioses, que les permiten vivir una vida habilidosa y fértil en esta tierra. La gente que vive en comunidad está continuamente involucrada en un proceso de creación mutua por medio del principio de la transferencia de los poderes creativos. Todo el trabajo que una persona hace contribuye a la entrega de vida a los que son miembros de la misma comunidad. Los parientes son creados no solamente por las capacidades reproductivas de las parejas de casados, sino también por medio del trabajo continuo llevado a cabo por los que están diariamente en contacto cercano. Cuando comen la comida procesada, o cazada, por los demás, las personas incorporan dentro de sí a los poderes personales de sus 'vidas de los pensamientos'. La comida que uno come es usualmente tanto el resultado de los esfuerzos de los demás como de uno mismo, y como tal, es un producto de sus pensamientos tanto como de los pensamientos propios. Durante la vida diaria, la gente está rodeada de poderosos productos de los pensamientos de otros - sus pucunas y trampas, sus peines y hamacas, las plantas de sus chacras, sus niños, su risa y lenguaje, el canto del ruiva, y hasta la casa en que viven...

Pero, las capacidades que los piaroa reciben de las cajas de cristal de los dioses para las artes culinarias continúan siendo las mismas que el terrible Kuemoi creó. En sus manos, son fuerzas monstruosas de depredación y canibalismo. Los dioses benévolos de la actualidad, en cambio, limpian continuamente estas fuerzas violentas de los tiempos míticos, volviéndolas hermosas antes de entregárselas a los piaroa, 
para que cada cual las guarde de manera segura en el interior de sus 'cuentas de conocimiento' (ver Overing 1985b, 1989). Cada persona debe ser vigilante con estas fuerzas interiores de los dioses para no causarse daño a sí mismo, o a los demás con quien uno vive. Cada cual tiene la responsabilidad de limpiar continuamente y embellecer sus fuerzas internas de vida, y de reflexionar constantemente sobre su uso. Cada noche, el poderoso ruiva, el chamán líder, gasta muchísima energía limpiando y embelleciendo estos poderes de brujería por medio de los cuales viaja por el multiverso. Esta limpieza es necesaria para lograr su fuerza, y proteger a todos los que viven con él. El uso inteligente de estos poderosos dones de los dioses permite que la gente viva una existencia social en la comunidad fértil, tranquila y segura. Una vida en la que ningún tirano loco puede existir. Por lo menos, ésta es la teoría. En los hechos, es imposible que alguien pueda mantener el completo control sobre las fuerzas de vida perversas dentro de sí. Este es el dilema que los piaroa enfrentan diariamente: las fuerzas de vida incorporadas en sus cuerpos que las personas no pueden domesticar son expulsadas como excretas. Estas excretas semen, sangre menstrual, orina, sudor, pus, vómito, excrementos, abortos - son considerados como particularmente potentes, pero son manifestaciones no controladas de la fertilidad de la persona, con una potencia perversa de impregnar a los parientes con enfermedades.

Sin embargo, las excretas son importantes para la salud y el poder de las personas. Como José Luis me explicó, se considera que una mujer que menstrúa está botando sus propias fuerzas incontroladas, algunas de las cuales son las fuerzas de las otras personas con las que vive que ha incorporado por inadvertencia. No obstante, hay un precio que pagar. En un canto de lamentación, escuché una vez a una mujer contando su culpa por la menstruación, su preocupación por estar sometiendo a sus hijos y a los hombres jóvenes al olor de su sangre. José Luis nos dijo que los chamanes también menstrúan, con un resultado muy similar al de las mujeres. Un chamán adquiere sus grandes poderes de brujería por medio de ritos de desangramiento menstrual dos veces al año. Para menstruar, se atraviesa la lengua con la cola de una raya. Al hacer esto, bota toda la 'suciedad', o la fertilidad incontrolada que ha acumulado de los otros miembros de su comunidad, como por ejemplo, de la sangre menstrual de sus mujeres. Este ritual también le permite 'mantener sus pensamientos en orden', limpiar sus perversidades incontroladas. Por lo tanto, contribuye a evitar que él se convierta en un tirano. El gran ruwia debe de velar cuidadosamente para detectar cualquier signo de hybris en su comportamiento personal.

La fertilidad incontrolada lo hace a uno insocial. Para los jóvenes, esto los puede conducir a la diarrea, al reírse inadecuadamente, y en general, al volverse exigente y difícil de convivir. Los jóvenes son curados por los chamanes, quienes les administran una limpieza para colocar sus 'pensamientos en orden'. Pero la fertilidad incontrolada de un chamán es un asunto mucho más serio (Overing 1985b). El chamán 
está involucrado con algunas de las fuerzas más peligrosas del multiverso: si se envenena con ellas se puede volver truculento, egocéntrico, agresivo, hasta paranoico - punzante en vez de divertido. En lugar de bromear, molestaría a los demás, causándoles rabia. A menudo los piaroa me hablaron, y en gran detalle, sobre las maneras cómo se protegen contra la posibilidad de que un tirano aparezca entre ellos. Tanto los hombres como las mujeres observan detenidamente el comportamiento de un poderoso ruzua para detectar signos de una falta de dominio. Una vez, en Maparæku vi a un grupo de mujeres que le estaban haciendo bromas a Carlos, molestándolo por haberse burlado demasiado duro de la comida de la 'gente blanca' (lo habíamos ofendido sin querer al haberle ofrecido de comer fideos con sardinas cuando él nos estaba enseñando sobre los cantos) Todo el mundo observó cuidadosamente a Carlos durante el tiempo en que progresaba para convertirse en un poderoso ruiva. Nadie se refería a él como 'rutua'hasta que no hubiese presentado exitosamente los tres grandes festivales del peligroso Sari - sin que ningún niño muera ni se enferme. Solamente después se le reconoció como rutua. Al proteger a todos los niños de los espíritus hambrientos de los muertos, demostró su 'dominio' sobre sus pensamientos - por lo menos hasta ese momento.

Capita, un antiguo poderoso ruzua que vivía en una comunidad vecina de Maparæku, no logró hacer esto tan bien. Enloquecido de celos cuando los miembros de su comunidad comenzaron a dejarlo para irse a vivir con Carlos, comenzó a maldecir y a enviar hechizos para atacar a los niños de su rival, y hasta de otras comunidades. Capita creía que todo el mundo estaba hablando mal de él, diciendo mentiras sobre él. Estaba sufriendo de paranoia, la enfermedad de locura de k'eræeu, la enfermedad de 'girar en círculos', de 'caer' de Kuemoi. Estaba sufriendo de la falta de control del tirano. De manera inusitada, todos los rutuatu del territorio se reunieron, y decidieron que la voluntad de Capita había sido irremediablemente envenenada. Para evitar más violencia en el futuro, tomaron la decisión de quitarle ceremonialmente todos sus pensamientos para la práctica chamánica, una tarea que emprendieron de manera exitosa. Después de esto, Capita se quedó viviendo solo con una niña huérfana que lo cuidaba. Ocasionalmente, sin embargo, Carlos lo invitaba a Maparæka para cantar con ellos de noche. Ya no había peligro, ya no tenía más las fuerzas de un poderoso brujo.

\section{Evitando al tirano: La poética del igualitarismo}

Lo que podemos percibir en el acto de narrar (performance) los relatos míticos es una filosofía política plena que afirma claramente, y con todas las letras, la necesidad del igualitarismo como el único camino posible para un modo humano de vida social. La preocupación política existente es la de impedir la emergencia del tirano. En el relato de las escenas míticas, los narradores revelan códigos de decoro y las artes de la folía: uno aprende aquellas formas de folía que permiten una existencia cómoda y apropiada, y aquellas que son destructivas. De este modo, la narración de 
క relatos revelan las lecciones sutiles de la folín de dos filos. El retrato de Erasmo del mensaje de Dama Locura ${ }^{11}$ se encaja bien en este caso.

Una buena razón por la que los piaroa rechazan inflexiblemente una existencia e-tructurada y cercada de reglas, es que las reglas y las regulaciones son demasiado lierales para tomar en cuenta las incongruencias cósmicas o sociales. La solución jerárquica a la socialidad es demasiado directa para tomar en cuenta las ironías - Is urdas de la existencia humana, y los rasgos grotescos escondidos en ella (Overing 0- 3, 2004). Para los piaroa, los matices de las relaciones interpersonales, las condiciones ctie ivas son demasiado complicadas - intelectual y afectivamente - así como también las intrusiones del paisaje cósmico traicionero e indómito dentro del ámbito de lo social. Este paisaje continúa existiendo en el aquí y ahora. El multiverso piaroa está motivado, animado, con mucho espacio para paisajes míticos malévolos. Se puede - omprender por qué, desde el punto de vista piaroa, la cuestión política crucial es la

$s$ iguiente: frente al fundamento mítico del desastre social y de la monstruosidad en el que aún deben de operar hoy en día, ¿cómo pueden realizar el arte de la vivencia social? Existe en esta cuestión una psicología social con la que los conceptos antropológicos no consiguen lidiar bien, y lo mismo puede decirse con respecto a la cuestión de los procesos igualitarios versus los jerárquicos. Ciertamente, el ioualitarismo piaroa, depende del uso contínuo de múltiples niveles de tropos, del

o sorprendente de la poética y del reconocimiento de los méritos de un fuerte sentido del humor del insulto.

Mi conclusión es que las sensibilidades sociales y políticas de los piaroa están moldeadas por una rica filosofía de la folín. De esta manera, en vez de reglas sociales y regulaciones, existe la necesidad de una psicología social matizada, esa filosofín exuberante de la folia, una evaluación constante de la folía cósmica. La folía está en el corazón de lo social. La condición social humana sólo puede ser realizada por medio del espiritu de la folía.

En otras palabras, el vínculo entre la poética piaroa (que evoca a los absurdos profundos de la existencia humana) y sus prácticas sociopolíticas es, hablando de manera "sociológica", un factor clave. Cada persona piaroa posee en sus bellas cuentas interiores de vida las fuerzas para comportamientos tiránicos locos. Está quedando claro que nuestra noción de los "sociológico", más que muchas otras nociones fundamentales, necesita de una buena limpieza general.

\section{¿Por qué el género de lo grotesco?}

El género de lo grotesco es usado de forma calculada por las narraciones míticas piaroa. ¿Cuál es su tarea? En esto, la sabiduría depende de la comprensión

Se trąta de una referencia a la obra de Erasmo de Rotterdam El Elogio de la Locura (folía), cuya persona en algunas traducciones aparece como la "señora Estulticia». 
del mensaje de lo grotesco. ¿Por qué debería de ser así? Mientras este saber sea parte integral de una doctrina igualitaria amazónica, no corresponde al saber convencional de la teoría sociológica modernista. ¿Por qué debería de ser así?

En parte, es de toda esa "corporalidad" que depende lo grotesco. La teoría modernista despoja al cuerpo de su escondrijo. Además, durante los siglos XVIII y XIX, los estudiosos occidentales mantuvieron una visión peyorativa de los grotesco, juzgándolo como una especie vulgar de lo cómico, destituido de seriedad. Era visto como un género de exageración ridículo y de lo fantástico. Más recientemente, han surgido interesantes re-evaluaciones del poder de este género, en parte debido al importante trabajo de Bakhtin sobre la poética y la fuerza política de lo grotesco.

En las evaluaciones recientes, una observación altamente interesante y relevante para nuestro acercamiento sobre la fuerza política de lo grotesco, es que se trata de un género más vinculado al realismo que a la fantasía. Ahora podemos hablar enfáticamente, y con razón, de su potencial como una fuerza sociológica. Es verdad, lo grotesco es extravagante. Pero no es fantástico. Nuestro acercamiento es que, por más extraño que sea el mundo grotesco, también es nuestro mundo (Bakhtin, 1968; Thompson, 1972). Defiendo el argumento que, al pertenecer a este género, el acto de narrar mitos tiene como primer y mayor objetivo expresar la naturaleza problemática de la existencia. Lo grotesco nos sacude en el sentido de transformar nuestra perspectiva sobre lo que la realidad realmente es. Nos hace ver el mundo real de otra manera. La sabiduría de una narración de un mito bien hecha es alcanzar esta meta. En el caso de los piaroa, el género de lo grotesco revela la locura del déspota: el déspota como bufón. El tirano a-social, solitario, con poder monstruoso y excesivo (el tirano es incapaz de establecer relaciones personales). Hace que el público se acuerde de que el mejor antídoto contra las pretensiones de grandeza y la avaricia es el espíritu de la irreverencia bromista. También hace que el público se acuerde del valor del humor para consigo mismo, puesto que todos los absurdos de su paisaje mítico están, por así decir, dentro de cada persona. Todas esas habilidades (de las artes culinarias) que, por un lado, propician la autonomía personal para cada adulto, masculino o femenino, y que posibilitan una comunidad de relaciones sociales, pueden, por otro lado, ser fácilmente destructiva de dicha vida, de dicha sociabilidad, de la libertad de la autonomía personal. Esta es el daño de la folía cósmica. Las relaciones igualitarias de convivialidad realmente deben ser cultivadas.

Como Peter Berger (1997) sugiere, lo cómico como modo de conocimiento ofrece una percepción de este lado bajo de la folia: sabiendo esto, y entrenándolos a la luz de esta sabiduría, podemos por algún tiempo, por lo menos, engañar las incongruencias cósmicas y cómicas de la existencia. Las artes de la folía, el papel que tienen en la realización de una socialidad cómoda, su relación con el conocimiento, y sus posibilidades, políticamente hablando, de libertad, puede ser buenas pistas de investigación para los antropólogos. 
Los piaroa conocen muy bien los peligros de la relación entre saber y poder. En la vida cotidiana, siempre están atentos a las señales que indican la emergencia de un tirano, de esa tiranía y egoísmo, de ese ego lleno de sí que se vuelve irrespetuoso de las relaciones personales, que se vuelve desdeñoso de la dignidad de los demás dentro de la comunidad en que vive, que ignora el carácter relacional del poder. La tiranía es una bobera, una tonterí; debe ser ridiculizada. Tal vez podemos entender mejor el hecho que el sentido occidental abstracto de Sociedad, con sus reglas jurídicas, sus estructuras jerárquicas, sus mecanismos pesadamente represivos, su impersonalidad - todas esas cosas - son ofensivas para la mayoría de los pueblos amazónicos. Diría que los pueblos de la Amazonía tienen una conciencia de poder bien desarrollada, y una rica poética para expresarla. La libertad es una cuestión política para ellos.

\section{Conclusión}

Hoy en día tenemos necesidad más que nunca de entablar el diálogo con aquellos que tienen formas narrativas diferentes de nuestras narrativas sobre la comunidad y la sociedad, la igualdad y la libertad. Nuestra manera monológica de proceder ha causado daño repetidas veces a los pueblos del mundo. Valores como 'libertad' e 'igualdad', siempre hacen parte de los marcos particulares de las actividades sociales, incluyendo sus historias particulares. ${ }^{12}$ En nuestro caso específico, estos valores emergen dentro del contexto de una sociedad estratificada, aunque dividida en otras configuraciones jerárquicas a lo largo del tiempo.

En los últimos veinte años, los gobiernos europeos, y especialmente en Gran Bretaña, la "cultura de la auditoria" ha conducido a un aumento draconiano del control gubernamental sobre las universidades (ver, en especial, Sue Wright y Chris Shore 1999, 2000; Wright 1998, 2003). Esta cultura de la auditoría y prestación de cuentas se funde con las tecnologías de policiamento y gerenciamento - las técnicas de la administración corporativa - modeladas en los valores del mundo de los negocios. La "prestación de cuentas" está considerada como el modelo de eficiencia. La vigilancia constante de la "productividad" tan deseada. Por lo tanto, los académicos no podemos, por medio de nuestro trabajo intelectual, transformar fácilmente estas fuerzas de estratificación. Tal vez no sirva de nada sugerirle a los auditores y los políticos que la productividad académica aumentaría muchísimo si es que las tareas de liderazgo fuesen llevadas a cabo con las 'artes de la convivialidad', o con un sabio espíritu de folía y una poética de la práctica. Tampoco sería una buena estrategia, por más tentador que parezca, que los académicos interactúen con los administradores con un espiritu de irrelevancia burlona, desmantelando todo signo de grandiosidad. Este juego sería considerado 'fuera de orden' y muy tonto -

Como Charles Taylor (1985:276-277) sostiene, la noción de 'iguales' no tiene una realidad independiente de cómo es inserta en un contexto específico de prácticas y un horizonte de entendimiento. 
un signo de debilidad. Generalmente, los líderes occidentales le dan mucho valor al protocolo formal. En los asuntos 'serios' de administración y gobiernos, las relaciones permanecen formales, y en gran parte exentas de sentido del humor. Atributos que los pueblos amazónicos verían como una ruptura del liderazgo (el dar órdenes rígidas o pronunciarse sobre reglas y reglamentos, demostrar arrogancia y condescendencia, procedimientos de distanciamiento), para nosotros occidentales son, al contrario, consideradas necesarias para los procesos burocráticos dentro de nuestras universidades y nuestros gobiernos. No obstante, la globalización tiene muchas facetas. Junto con la globalización uni-direccional y no dialógica, también hay una globalización que está sustentada en la estética de la diversidad, la 'poética de la relación', como Glissant dice (1990, 1996, 1997; también ver Passes 2003). Este universo sin fronteras de relaciones pluralistas fomenta un tipo de relación que refleja un estilo de pensamiento no-absolutista, no-esencialista. Por medio de esto, las conversaciones académicas con interesantes Otros pueden ciertamente prosperar.

Por otro lado, no hay ninguna razón que los académicos estemos encuadrados por los valores de juicio de la burocracia y la auditoría. Cuando de enseñanza se trata, día a día debemos crear y defender un horizonte de referencia diferente. Este es un horizonte gracias al cual el espíritu de 'colegialidad' (collegiality) ${ }^{13}$ puede ser promovido. Un espíritu de colegialidad es el único adecuado para una comunidad de iguales que depende tanto de la mutualidad afectiva como intelectual. La orientación de valor que engendra el espíritu de colegialidad también cultiva la tranquilidad, el buen ánimo, y el juego de amplio ámbito, necesarios para el pensamiento creativo. Con esta finalidad, los académicos pueden encontrar inspiración en las filosofías amazónicas de la folía. La salud creativa de las comunidades de académicos, así como la de los pueblos amazónicos, requiere de un sentido de comunidad que junte la estética, el valor moral y la socialidad en las prácticas del día a día. Aquí estoy apelando a la supervivencia de una filosofía dentro de nuestro propio pasado, pero a una filosofía más renacentista que iluminista.

Por medio de un fuerte espíritu de colegialidad, podemos comprendernos mejor, conscientes de los monstruos dentro y fuera de nosotros mismo y de los demás. Cabe anotar que la propia manifestación de un comportamiento de folía conocedor sería un signo de que las habilidades usadas por los académicos en sus prácticas diarias están, efectivamente, manteniendo a la hybris y a la tiranía (incluyendo la nuestra propia) bajo control. Es por medio de las habilidades de lo lúdico que se puede generar buen ánimo. $Y$, es solamente por medio del buen ánimo que los académicos pueden ser capaces de crear redes de 'colegialidad' amplios, fluidos y pluralísticos, a través de las cuales establecer conversaciones interesantes, y al hacer esto, encontrar otras maneras de ver el mundo.

13 La palabra Collegiality en Inglés se refiere al espíritu de compañerismo, honestidad y respeto intelectual mutuo existente entre los miembros de los mismos colleges, o colegios, de enseñanza dentro de las instituciones universitarias. 


\section{Bibliografía}

Abercrombie, Nicholas, Stephen Hill and Bryan Turner, 1986 Sovereign Individuals of Capitalism, London: Allen \& Unwin.

Amit, Vered

2000 The university as panopticon: moral claims and attcks on academic freedom. Marilyn Strathern (ed.) Audit Cultures, pp.215-235, London y New York: Routledge.

Asad, Talal. (ed.)

1975 Anthropology and the Colonial Encounter. London: Ithaca Press and Humanities Press.

Bakhtin, Mikhail

1968 Rabelais and his World, Cambridge, Mass: MIT Press

Baier, Annette

1994 Moral Prejudices, Cambridge, Mass: Harvard university Press.

Bauman, Zymunt

1995 Life in Fragments: Essays in Postmodern Morality, Oxford: Blackwell.

Belaunde, Luisa Elvira

1994 Parrots and oropendolas: the aesthetics of gender relations among the AiroPai of the Peruvian Amazon. Joumal de la Société des Américanistes 80: 95111.

2000 The convivial self and the fear of anger amongst the Airo-Pai of Amazonian Peru. Joanna Overing and Alan Passes (eds.) The Anthropology of Loze and Anger, pp. 209-220, London and New York: Routledge.

2001 Viviendo Bien: Género y Fertilidad Entre Los Airo-Pai de la Amazonía Permana, Lima: CAAAP.

Benhabib, Sevla

1992 Situating the Self: Gender, Community and Postmodernism in Contemporary Ethics, Cambridge: Polity.

Berger, Peter

1997 Redeeming laughter: The Comic Dimension of Human Experience. New York: Walter de Gruyte. 
Bhabha, Homi

1994 The Location of Culture, London: Routledge.

Brady, Ivan

1991 Harmony and Argument: Bringing Forth the Artful Science. I. Brady (ed.) Anthropological Poetics, Savage, Md: Rowman-Littlefield.

de Certeau. Michel

1997 Culture in the Plural, Minneapolis: University of Minnesota.

1984 The Practice of Everyday Life, Berkeley and Los Angeles: University of California Press.

de Oliveira, Adolfo

2003 Of Life and Happiness: Morality, Aesthetics, and Social Life among the Southeastern Amazonian Mebengokré (Kayapo), as Seen from the Margins of Ritual, Tesis de doctorado, University of St Andrews.

Dumont, Louis

1977 From Mandeville to Marx, Chicago and London: University of Chicago Press.

Echeverri, Juan Alvaro

2000 The first love of a young man: salt and sexual education among the Uitoto Indians of Lowland Colombia, in Joanna Overing and Alan Passes (eds.) The Antluropology of Love andAnger, pp. 33-45, London and New York: Routledge.

Fabian, Johannes

1983 Time and the Other; How Anthropology Makes its Object, New York: Columbia University Press.

1998 Moments of Freedom: Anthropology and Popular Culture, Charlottesville: University Press of Virginia.

Fardon, Richard (ed.)

1995 Counterworks: Managing the Diversity of Knowledge, London: Routledge.

Feyerabend, Paul

1975 Against Method, London: New Left Books.

Gonçalves, Marco Antonio

2000 A woman between two men and a man between two women: the production of ealousy and the predation of sociality amongst the Paresi Indians of Mato Grosso (Brazil), Joanna Overing and Alan Passes (eds.) 2000 The 
Anthropology of Love and Anger, pp. 235-251, London and New York: Routledge.

Glissant, Edouard,

1990 Poétique de la relation (Poétique III), Gallimard, Paris.

1996 Introduction à une poétiqu e du divers, Gallimard, Paris.

1997 Traité du tout-monde (Poétiquie IV), Gallimard, Paris.

Goodman, Nelson

1968 langunges of art: an approach to a theory of symbols, New York: Bobbs Merrill.

1978 Ways of Worldmaking, Brighton: Harvester press.

Gow, Peter

2000 Helpless - the affective preconditions of Piro social life. Joanna Overing and Alan Passes (eds.) The Anthropology of Love and Anger: the Aesthetics of Conviviality in Native Amazonia, pp. 46-63, London and New York: Routledge.

Heckler, Serina

2004 Tedium and creativity: the valorization of manioc cultivation and

Piaroa women', in JRAI, Vol. 10, no. 2:241-261.

Hesse, Mary

1984 The cognitive claims of metaphor. Metaphor and Religion, Theolinguistics 2, J.P. van Noppen (ed.). Brussels.

Ingold, Tim.

2000 The Perception of the Environment: Essays in livelihood, divelling and skill, London: Routledge.

Hymes, Dell

1981 In Vain I Tried to Tell You: Essays in Native American Ethnopoetics, Philadelphia: University of Pennsylvania.

Kidd, Stephen

2000 Knowledge and the practice of love and hate among the Enxet of Paraguay', in Joanna Overing and Alan Passes (eds.) The Anthropology of Love and Anger, pp. 114-132, London and New York: Routledge.

Kulick, Don

1992 Language Shift and Cultural Reproduction: Socialization, self, and syncretism in a Papua New Guinean village, Cambridge: Cambridge University Press. 
Lagrou, Els

1998 Cashinahua Cosmovision: A Perspectival Approach to Identity and Alterity, PhD Thesis, University of St Andrews.

2000 Homesickness and the Cashinahua self: a relection on the embodied condition of relatedness. Joanna Overing and Alan Passes (eds.) The Anthropology of Love and Anger, pp. 152-169, London and New York: Routledge.

Londoño-Sulkin, Carlos

2000 Though it comes as evil, I embrace it as good: a reflection on the embodied condition of relatedness. Joanna Overing and Alan Passes (eds), The Anthropology of Love and Anger, pp. 170-186, London and New York: Routledge.

Macpherson, C.B.

1962 The Political Theory of Possessive Individualism, Oxford and London: University of Oxford Press.

MacIntyre, Alasdaire

1985 After Virtue: a Study in Moral Theory, second edition, London: Duckworth.

Mason, Peter.

1990 Deconstructing America: Representations of Others, London: Routledge.

Marien, Mary Warner

1988 Hover Culture': Shifting into Neutral. Christian Science Monitor, 5..

Mauss, Marcel

1985 A category of the human mind: the notion of person; the notion of self' (translated by W. D. Halls), in Michael Carrithers, Steven Collins (eds.)

The Category of the Person: Anthropology, Philosophy, History, pp.1-25, Cambridge: Cambridge University Press.

O'Donnell, Mike

2003 Dynamics of Change-Impacts on 'Education. Conference Paper, Dynamics of Change in Higher Education, C-SAP Centre for Learning and Teaching Sociology, Anthropology and Politics, 3-4 April.

Overing, Joanna (ed.)

1985a Reason and Morality, London: Tavistock.

1985b There is no end of evil: the guilty innocents and their fallible god. David Parkin (ed.) The Anthropology of Evil, Oxford: Basil Blackwell. 
1987 Translation as a creative process: the power of the name, in Ladislav Holy (ed.)Comparative Antliropology, pp. 70-87. Oxford: Basil Blackwell.

1989 The aesthetics of production: The Sense of Community among the Cubeo and Piaroa. Dialectical Antinropology 14:159-175.

1993 The anarchy and collectivism of the 'primitive' other': Marx and Sahlins in the Amazon. Chris Hann (ed), Socialism: Ideals, Ideologies, and Local Practice, pp. 43-58. ASA Monographs 31, Routledge.

1998 Is an anthropological translation of the 'unhomely' possible, or desirable? ASCA: Intellectual Traditions in Movement (The Amsterdam School for Cultural Analysis yearbook), pp. 101-116.

2000 The efficacy of laughter: the ludic side of magic within Amazonian Sociality. Joanna Overing \& Alan Passes (eds.) The Antliropology of Love and Anger, pp. 64-81, London and New York: Routledge.

2003a In Praise of the Everyday: Trust and the Art of Social Living in an Amazonian Community. Ethmos, Vol, 68:3:293-316.

2004 The Grotesque Landscape of Mythic 'Before Time'; the Folly of Sociality in 'today time': an egalitarian aesthetics of human existencepp. Elke. Mader \& Ernst Halbmayer, (eds), Kultur, Raum, Landschaft: Zur Bedeutung des Raumes in Zeiten der Globalität. Frankfurt am Main: Brandes \& Apsel/ Südwind, pp.69-90.

Overing, Joanna \& Alan Passes

2000 Introduction: Conviviality and the opening up of Amazonian anthropology. Joanna Overing \& Allan Passes (eds.), The Anthropology of Love and Anger: the Aesthetics of Conviviality in Native Amazonia, pp. 1-30, London: Routledge

Overing Joanna \& Alan Passes (eds.)

2000 The Antliropology of Love and Anger: the Anesthetics of Conviviality in Native Amazonia, London and New York: Routledge.

Passes, Alan

2000 The value of working and speaking together: a facet of Pa'ikwené (Palikur) conviviality. Joanna Overing and Alan Passes (eds.) The Anthropology of Lowe and Anger, pp. 97-113, London and New York: Routledge.

2003 You Are What You Speak, or Are You? Identity, language, sociocultural change, and the Pa'ikivené. Estudios Latinoamericanos 23: 91-108.

Rapport, Nigel \& Joanna Overing

2000 Alterity', Culture, Gender, Society', The Unhomely. Social and Culturnl Anthropology: The Key Concepts, London: Routledge. 
Riviere, Peter

1984 Individual and Society in Guiana, Cambridge: Cambridge University Press. 2000 The more we are together. Joanna Overing and Alan Passes (eds.) The Anthropology of Love and Anger, pp. 235-251, London and New York: Routledge.

Said, Edward

1978 Orientalism, London: Penguin.

Santos-Granero, Fernando

2000 The Sisyphus Syndrome, or the struggle for conviviality in Native Amazonia. Joanna Overing and Alan Passes (eds.) The Anthropology of Love and Anger, pp. 268-287, London and New York: Routledge.

Shore, Chris. and Susan Wright

1999 Audit culture and anthropology: neo-liberalism in British Higher Education. JRAI 5:4 pp557-575.

2000 Coercive Accountability: The New Audit Culture and its Impact on Anthropology. Marilyn Strathern (ed.) Audit Cultures, London and New York: Routledge, pp. 57-89.

Strathern, Marilyn

2000 Audit Cultures, London and New York: Routledge.

Taylor, Charles

1985 Philosophical Papers 1 and 2, Cambridge: Cambridge University.

Tedlock, Dennis and Bruce Mannheim

1995 Introduction. Dennis Tedlock and Bruce Mannheim, The Dialogic Emergence of Culture. Urbana and Chicago: The University of Illinois.

Thomas, Nicolas

1994 Colonialism's Culture, Cambridge: Polity Press.

Thomson, Philip

1972 The Grotesque. Methuen \& Co.

Toulmin, Stephen

1990 Cosmopolis: The Hidden Agenda of Modernity, Chicago: The University of Chicago Press. 
Vernant, Jean-Pierre

2002. The Universe, the Gods, and Mortals. London: Profile Books.

Wagner, Roy

1991 Poetics and the Recentering of anthropology. Ivan Brady (ed.) Anthropological Poetics, Savage, Md: Rowman-Littlefield.

Wright, Susan

1998 The politicalization of culture. Anthropology Today: Vol. 14 No 1:7-15

2003 Role of C-SAP in a Context of Change, Conference Paper, Dynamics of Change in Higher Education, C-SAP Centre for Learning and Teaching Sociology, Anthropology and Politics, 3-4 April. 